\title{
(C) OPEN ACCESS \\ Cytotoxic effects of heated tobacco products (HTP) on human bronchial epithelial cells
}

\author{
Noel J Leigh, Phillip L Tran, Richard J O'Connor, Maciej Lukasz Goniewicz
}

\begin{abstract}
- Additional material is published online only. To view please visit the journal online (http://dx.doi.org/10.1136/ tobaccocontrol-2018-054317).

Department of Health Behavior, Roswell Park Comprehensive Cancer Center, Buffalo, New York, USA

Correspondence to Dr Maciej Lukasz Goniewicz, Department of Health Behavior, Division of Cancer Prevention and Population Sciences, Roswell Park Comprehensive Cancer, Buffalo, NY 14203, USA; maciej.goniewicz@roswellpark. org
\end{abstract}

Received 16 February 2018 Revised 1 August 2018 Accepted 13 August 2018 Published Online First 5 September 2018
ABSTRACT

Background Heated tobacco product(s) (HTP), also called heat-not-burn products, are a re-emerging class of tobacco products that purport to reduce health risk compared with smoking combustible tobacco products. This study examined the potential toxic effects of inhaling emissions from an HTP in comparison with electronic and combustible tobacco cigarettes. Methods Inhalation toxicity of HTP (IQOS; tobacco flavour), e-cigarette (MarkTen; tobacco flavour) and tobacco cigarette (Marlboro Red) was examined in vitro using an air-liquid interface with human bronchial epithelial cells (H292). Cells were exposed directly to 55 puffs from the e-cigarette, 12 puffs from the HTP and 8 puffs from the tobacco cigarette to equilibrate nicotine delivery to the cells across products. Cytotoxicity was measured using neutral red uptake and trypan blue assays. Cytotoxic effects of each tested product (HTP, e-cigarette and tobacco cigarette) were compared with an air control. Release of inflammatory markers (cytokines) was measured using ELISA.

Results The HTP showed higher cytotoxicity compared with the air controls using the neutral red assay. The HTP also showed higher cytotoxicity than the e-cigarette, but lower cytotoxicity than the combustible cigarettes using the same assay. A significant increase in cytokines levels, compared with air controls, was observed postexposure to tobacco smoke but not to emissions from HTP or e-cigarette aerosol.

Discussion Using limited cytotoxic measures, the HTP showed reduced cytotoxicity relative to a combustible cigarette but higher toxicity than an e-cigarette. More comprehensive testing is needed to determine long-term effects of inhaling emissions from HTP.

\section{BACKGROUND}

In conventional cigarettes, once tobacco is heated above $600^{\circ} \mathrm{C}$, combustion occurs, and smoke containing harmful chemicals is released. ${ }^{1}$ Heated tobacco product(s) (HTP) release nicotine-containing emissions without burning tobacco. These products heat rather than burn tobacco, using an electronically controlled heating element. Hypothetically, by reducing the formation temperature, HTP products may emit lower levels of tobacco combustion byproducts and show reduced toxicity compared with combustible tobacco cigarettes. Some early models of HTP products were developed in the late 1980s; however, they did not reach a significant number of consumers and were withdrawn from the market. ${ }^{1}$ The HTP IQOS device was developed by Philip Morris International (PMI) and launched in international markets in mid-2014. According to manufacturer data, IQOS devices heat tobacco to temperatures up to $350^{\circ} \mathrm{C}$, avoiding combustion. $^{2}$

In December 2016, PMI submitted an application to the US Food and Drug Administration for their HTP IQOS to be authorised as a modified risk tobacco product. Claims of lowered risk of IQOS (non-combustible tobacco product) compared with conventional cigarettes (combustible cigarettes) are based almost exclusively on industry-funded research, and reliable independent research is not available to support these claims as of early 2018. A PMI-funded study reported a $90 \%$ reduction in cytotoxicity, determined by the neutral red uptake assay and the mutagenic potency in the mouse lymphoma assay, between HTP versus combustible tobacco cigarettes. ${ }^{3}$ Results showed only minor histopathological alterations and minimal cytotoxicity on HTP emission exposure compared with combustible cigarette smoke ( $1 \%$ for HTP vs $30 \%$ for tobacco cigarette). Among the 14 proinflammatory mediators analysed, only five exhibited significant shifts with HTP exposure compared with 11 on combustible cigarette smoke exposure. ${ }^{4}$ Transcriptomic and metabolomic analysis indicated a general reduction of the impact in HTP emission-exposed samples with respect to tobacco smoke-exposed controls ( $79 \%$ lower biological impact compared with tobacco smoke). ${ }^{4}$ In the 90-day inhalation exposure study, PMI examined microRNA (miRNA) levels in the bronchoalveolar lavage fluid from lungs of Sprague Dawley rats exposed to HTP compared with tobacco smoke. ${ }^{5}$ Transcriptomic and metabolomics study performed on Sprague Dawley rats exposed to tobacco smoke or HTP emissions showed that only tobacco smoke caused global miRNA downregulation in nasal epithelium and lung parenchyma. Upregulation of specific miRNA species indicated that they were causal elements in the inflammatory response in tobacco smoke-exposed lungs, but they were reduced after HTP emission exposure. ${ }^{6}$

Although all of above-cited studies evaluated relative effects of IQOS to combustible cigarettes, none of the studies cited above compared toxicity of IQOS to e-cigarettes. Independent research is therefore urgently needed to provide a balanced view on absolute potential health impact of HTP and the relative effects compared with other potential reduced-risk products like e-cigarettes.

Since there is a critical knowledge gap in the potential impact of HTP emissions on respiratory health, this study examined the potential cytotoxic effects of inhaling emissions from an HTP in comparison with the electronic and combustible cigarettes using an in-vitro model. 


\section{MATERIALS AND METHODS Products}

Three nicotine-containing products made by PMI were used in this study: (1) HTP (IQOS; with the PMI Amber HeatSticks (HEETS), (2) e-cigarettes (MarkTen brand; 3.5\% nicotine, tobacco flavoured) and (3) tobacco cigarette (Marlboro Red $85 \mathrm{~mm})$. The HTP was purchased in Florence, Italy, and the electronic and tobacco cigarettes were purchased in Buffalo, USA.

\section{Generation of emissions from tested products}

Emissions from tested products were generated using a Borgwaldt LX-1 (Richmond, Virginia, USA) single-port, piston-operated smoking machine. The Health Canada Intense puffing protocol was used with the following conditions: $2 \mathrm{~s}$ puff duration, every $30 \mathrm{~s}$, with a $55 \mathrm{~mL}$ puff volume. The number of puffs varied, depending on the product tested, to represent one smoking session. This was accomplished by using one tobacco cigarette and one HTP HEETS, and then matching nicotine delivery from one HTP HEETS to an e-cigarette. In our previous smoking-machine study using the Health Canada Intense puffing protocol, ${ }^{7}$ we found that one tobacco cigarette delivered $2.1 \mathrm{mg} /$ cigarette in 8 puffs, the HTP delivered $1.4 \mathrm{mg} / \mathrm{HEETS}$ in 12 puffs and the e-cigarette delivered a similar amount of nicotine as the HTP $1.3 \mathrm{mg} / \mathrm{session}$ with 55 puffs. $^{7}$ Air exposures (control), 55 puffs over a total of $30 \mathrm{~min}$, were run during each experiment.

\section{Cell exposure conditions}

Cells were acutely exposed, on three separate days, to emissions (both gas phase and particulates), aerosol or smoke from tobacco products using an air-liquid interface (ALI) interface. The NCI-H292 human bronchial epithelial cell line (ATCC) was plated on $0.4 \mu \mathrm{m}$ permeable supports (PS) 24 hours prior to experimentation under previously described conditions. ${ }^{8}$ Immediately prior to exposure, the media were removed from the apical side of the PS, and cell-containing inserts $(n=3)$ were placed in the ALI chamber. While the apical side of the cells were directly exposed to either: (1) an air control, (2) emissions from HTP, (3) aerosol from e-cigarettes or (4) smoke from tobacco cigarettes, fresh media were cycled over the basal side of the PS at a flow rate of $5 \mathrm{~mL} / \mathrm{min}$. After exposure, the apical side was resubmerged with complete or neutral red media until assay measurements 2.5 hours later. The ALI chamber was cleaned with methanol and distilled water between each of the four exposure conditions. A detailed description of this exposure system can be found in our previous study ${ }^{8}$ and online supplementary materials.

\section{Toxicity assays}

After 2.5 hours, cytotoxicity of exposed H292 cells was measured using two assays: neutral red uptake and trypan blue assays. The neutral red uptake assay provides a quantitative estimation of the number of metabolically active cells attached to the PS, based on the ability of viable cells to incorporate and bind the supravital dye neutral red into lysosomes. ${ }^{9}$ The trypan blue assay, a cell viability assay, is based on the principle that live cells possess intact cell membranes that exclude certain dyes, such as trypan blue, whereas dead cells do not. ${ }^{10}$ This assay measured the number of live cells attached to the PS (removed by trypsin) and the number of dead cells in the fresh apical media. Cytokines released into the fresh apical media were measured as an indicator of cell inflammatory response. Six cytokines (interleukin (IL)-1 $\beta$, IL-6, IL-10, CXCL1, CXCL2 and CXCL10) were measured using commercially available ELISA kits (Abcam and

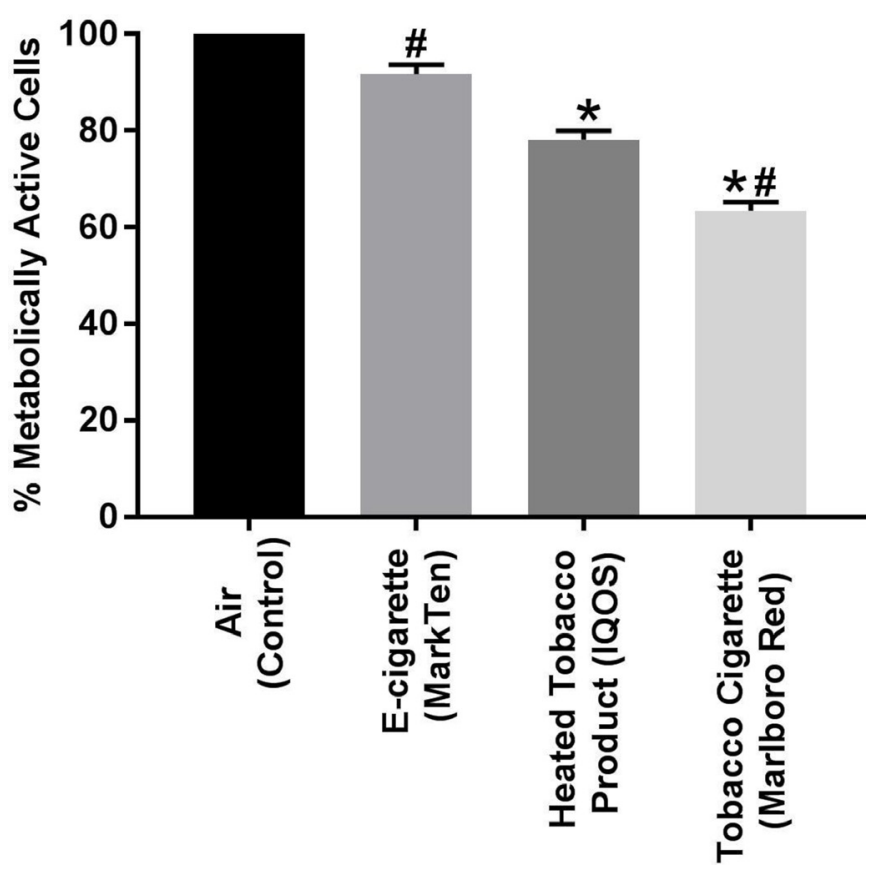

Figure 1 Metabolic activity (neutral red assay) from H292 bronchial epithelial cells directly exposed using an air-liquid interface to emissions from heated tobacco product (HTP), e-cigarette, combustible tobacco cigarette and air (controls). Emissions were generated from a MarkTen electronic cigarette (55 puffs), IQOS HTP (12 puffs/heetstick) and Marlboro Red combustible cigarette (eight puffs/cigarette). *Significant difference compared with the air control $(p<0.05)$. "Significant difference compared with IQOS product $(p<0.05)$.

R\&D System) following the manufacturers' protocols. These cytokines were chosen as a panel of inflammatory markers commonly used in in-vitro, in-vivo and clinical human studies. Changes in those markers have been shown to correlate with several clinically relevant outcomes and diseases. ${ }^{11-15}$ A detailed description of these assays can be found in our previous study ${ }^{8}$ and online supplementary materials.

\section{Statistical analysis}

Statistical analysis was performed using Prism V.6.07 (GraphPad). Kruskal-Wallis non-parametric tests and Dunn multiple comparison tests were performed for each study outcome to compare: (1) each product versus air controls, (2) combustible cigarettes versus HTP and (3) e-cigarettes versus HTP. All experiments were performed in triplicate, with each outcome measured three times per experiment (three wells per chamber).

\section{RESULTS}

Metabolic activity of $\mathrm{H} 292$ cells decreased significantly after exposure to HTP emissions compared with the air control $(p=0.002$, figure 1). Exposure to combustible tobacco smoke but not to e-cigarette aerosols also resulted in decreased cell viability $(\mathrm{p}<0.001$, online supplementary figure 1$)$ and metabolic activity $(p<0.001$, figure 1$)$, compared with the air controls. The neutral red assay, but not the trypan blue assay, revealed that IQOS emissions were significantly more toxic compared with e-cigarette aerosol ( $\mathrm{p}=0.044$, figure 1 and online supplementary figure 1$)$.

We were only able to detect IL- $1 \beta$ and IL- 6 released to media after exposure to all tested products; all other cytokine levels were below the limit of quantitation. There was no statistically significant differences between cytokines levels released 
postexposure to HTP emissions compared with air controls (IL-1 $13: 13.7 \pm 5.1$ vs $13.5 \pm 6.4$; IL-6: $6.9 \pm 2.1$ vs $11.8 \pm 3.2 \mathrm{pg} / 10^{7}$ cells; mean $\pm \mathrm{SD}$; all $\mathrm{p}>0.05$, online supplementary figures 2 and 3). HTP showed reduced release of cytokines compared with combustible cigarettes (IL-1 $\beta$ : $13.7 \pm 5.1$ vs $133.6 \pm 41.9$; IL-6: $6.9 \pm 2.1$ vs $65.5 \pm 21.7 \mathrm{pg} / 10^{7}$ cells; all $\mathrm{p}<0.05$, online supplementary figures 2 and 3). Levels of cytokines measured postexposure to HTP did not differ statistically from levels detected postexposure e-cigarettes (IL-1 $\beta$ : $13.7 \pm 5.1$ vs $12.9 \pm 4.7$; IL-6: $6.9 \pm 2.1$ vs $12.2 \pm 2.7 \mathrm{pg} / 10^{7}$ cells; all $\mathrm{p}<0.05$, online supplementary figures 2 and 3). Smoke generated from tobacco cigarettes increased cytokine levels compared with air controls, as well as the two other products $(\mathrm{p}<0.05)$.

\section{DISCUSSION}

This pilot study used an established ALI system to examine the cytotoxic and inflammatory effects of an HTP. Our results show that emissions from HTP caused damage to human bronchial epithelial cells relative to air controls. At the same time, HTP emissions showed lower toxicity compared with combustible cigarettes but higher toxicity compared with e-cigarettes. Our data suggest that use of IQOS products may lead to increased risk of respiratory health impairment, and although this risk may be reduced compared with smoking tobacco cigarettes, it is likely to be higher than risk from vaping e-cigarettes. ${ }^{16}$ However, it is important to note that the data presented have shown the relative effects of acute exposure to three different tobacco products and that further research is needed to determine the long-term health effects of the HTP product use.

In addition to the cytotoxicity results, we measured two important markers of inflammatory response. Cytokine IL-1 $\beta$ is involved in a variety of cellular activities, including cell proliferation, differentiation and apoptosis. Cytokine IL-6 is primarily produced at sites of acute and chronic inflammation and has been implicated in a wide variety of inflammation-associated disease states. In summary, we found that bronchial epithelial cells exposed to HTP emissions released less IL- $1 \beta$ and IL-6 than cells exposed to cigarette smoke. Additionally, no differences in cytokine concentrations were found between the e-cigarette and the HTP. The rapid death of cells exposed to tobacco smoke may have resulted in low levels of cytokines measured in our study since the proinflammatory activity of dead cells decays over time, presumably as the active cell components are degraded. While it is possible that in some situations intracellular stores of proinflammatory cytokines might be released on cell disintegration and cause inflammation, most of these mediators have restricted expression in cells and therefore cannot account for how the cells induce inflammation on death. ${ }^{17}$

An important limitation of our study is that we have used a single type of immortalised cell line to examine cytotoxicity. Although the ALI exposure provides a novel and specific exposure approach for performing the biological study on health effects related to inhalation of emerging tobacco products, extrapolating data from in-vitro studies to human risks remains hypothetical. ${ }^{18}$ This model may not recapitulate how these products affect tissues and do not aim to estimate any harmful effects in IQOS users. Future in-vitro studies with organotypic models as well as in-vivo animal studies are needed to confirm our findings. When real-life data on IQOS users' behaviours and puffing topography are available, future studies should adopt an appropriate exposure protocol that reflects real-life product use conditions. ${ }^{19}$ Finally, since our study focused on the acute toxic effects of HTP, our observations require verification in chronic exposure models, more relevant to regular use of HTP.

\section{What this paper adds}

- The extent to which heated tobacco product(s) (HTP) impact respiratory health is currently not defined.

- We tested cytotoxicity of HTP using cell viability and metabolic activity assays and examined the release of inflammatory cytokines in bronchial epithelial cells. These cells were exposed in vitro directly to HTP emissions and the results were compared with the observed effects after exposure to air (controls), e-cigarette aerosols and smoke from combustible tobacco cigarettes.

- We found that emissions from HTP damaged bronchial epithelial cells, and their cytotoxic effect was higher compared with e-cigarettes but lower compared with combustible tobacco cigarettes.

Contributors MLG contributed to the conception of the work. MLG and NJL contributed to data analysis. MLG, NJL and RJO drafted the manuscript. NJL and PLT ran all experiments. All authors approved the final version of the manuscript. MLG has full access to all study data and takes responsibility for the integrity of the data and accuracy of the data analysis.

Funding Research reported in this publication was supported by the National Cancer Institute of the National Institutes of Health under Award Number P01 CA 200512 and P30 CA 016056.

Disclaimer The content is solely the responsibility of the authors and does not necessarily represent the official views of the National Institutes of Health.

Competing interests MLG reports grants from and served as an advisory board member to pharmaceutical companies that manufacture smoking cessation drugs. RJO was a member of the FDA Tobacco Products Scientific Advisory Committee which considered Philip Morris International's modified risk application for IQOS in January 2018. Other authors declare no conflict of interest.

\section{Patient consent Not required.}

Provenance and peer review Not commissioned; externally peer reviewed.

Open access This is an open access article distributed in accordance with the Creative Commons Attribution Non Commercial (CC BY-NC 4.0) license, which permits others to distribute, remix, adapt, build upon this work non-commercially, and license their derivative works on different terms, provided the original work is properly cited, appropriate credit is given, any changes made indicated, and the use is non-commercial. See: http://creativecommons.org/licenses/by-nc/4.0/.

\section{REFERENCES}

1 Caraballo RS, Pederson LL, Gupta N. New tobacco products: do smokers like them? Tob Control 2006;15:39-44

2 Smith MR, Clark B, Lüdicke F, et al. Evaluation of the Tobacco Heating System 2.2 Part 1: description of the system and the scientific assessment program. Regul Toxicol Pharmacol 2016;81:S17-26.

3 Schaller JP, Keller D, Poget L, et al. Evaluation of the Tobacco Heating System 2.2 Part 2: chemical composition, genotoxicity, cytotoxicity, and physical properties of the aerosol. Regul Toxicol Pharmacol 2016;81:S27-47.

4 Zanetti F, Titz B, Sewer A, et al. Comparative systems toxicology analysis of cigarette smoke and aerosol from a candidate modified risk tobacco product in organotypic human gingival epithelial cultures: a 3-day repeated exposure study. Food Chem Toxicol 2017; 101:15-35.

5 Wong ET, Kogel U, Veljkovic E, et al. Evaluation of the Tobacco Heating System 2.2. Part 4: 90-day OECD 413 rat inhalation study with systems toxicology endpoints demonstrates reduced exposure effects compared with cigarette smoke. Regul Toxicol Pharmacol 2016;81:S59-S81.

6 Zanetti F, Sewer A, Mathis C, et al. Systems toxicology assessment of the biological impact of a candidate modified risk tobacco product on human organotypic oral epithelial cultures. Chem Res Toxicol 2016;29:1252-69.

7 Leigh NJ, Palumbo MN, Marino AM, et al. Tobacco-specific nitrosamines (TSNA) in heated tobacco product IQOS. Tob Control 2018;27:S37-8.

8 Leigh NJ, Lawton RI, Hershberger PA, et al. Flavourings significantly affect inhalation toxicity of aerosol generated from electronic nicotine delivery systems (ENDS). Tob Control 2016;25:ii81-7 
9 Repetto G, del Peso A, Zurita JL. Neutral red uptake assay for the estimation of cell viability/cytotoxicity. Nat Protoc 2008;3:1125-31.

10 Strober W. Trypan blue exclusion test of cell viability. Curr Protoc Immunol 2001;Appendix 3:A3. B. 1-3.

11 Kim V, Rogers TJ, Criner GJ. New concepts in the pathobiology of chronic obstructive pulmonary disease. Proc Am Thorac Soc 2008;5:478-85.

12 Lappalainen U, Whitsett JA, Wert SE, et al. Interleukin-1 beta causes pulmonary inflammation, emphysema, and airway remodeling in the adult murine lung. Am J Respir Cell Mol Biol 2005;32:311-8.

13 Barnes PJ. Immunology of asthma and chronic obstructive pulmonary disease. Nat Rev Immunol 2008;8:183-92.

14 Al-Alwan LA, Chang Y, Mogas A, et al. Differential roles of CXCL2 and CXCL3 and their receptors in regulating normal and asthmatic airway smooth muscle cell migration. J Immunol 2013;191:2731-41.
15 Yoshikawa M, Wada K, Yoshimura T, et al. Increased CXCL10 expression in nasal fibroblasts from patients with refractory chronic rhinosinusitis and asthma. Allergol Int 2013;62:495-502.

16 Moazed F, Chun L, Matthay MA, et al. Assessment of industry data on pulmonary and immunosuppressive effects of IQOS. Tob Control 2018:1-6.

17 Rock KL, Kono H. The inflammatory response to cell death. Annu Rev Pathol 2008;3:99-126.

18 Johnson MD, Schilz J, Djordjevic MV, et al. Evaluation of in vitro assays for assessing the toxicity of cigarette smoke and smokeless tobacco. Cancer Epidemiol Biomarkers Prev 2009;18:3263-304.

19 Lüdicke F, Picavet P, Baker $\mathrm{G}$, et al. Effects of switching to the tobacco heating system 2.2 menthol, smoking abstinence, or continued cigarette smoking on biomarkers of exposure: a randomized, controlled, open-label, multicenter study in sequential confinement and ambulatory settings (Part 1). Nicotine Tob Res 2018;20:161-72. 